with bicarbonate fluid $(p<0.05)$. Mean arterial blood pressure fell at a mean rate of $3.9(0.90) \mathrm{mm} \mathrm{Hg} / \mathrm{hour}$ during dialysis with acetate fluid $(\mathrm{p}<0.01)$ and $1.4(0.52) \mathrm{mm} \mathrm{Hg} /$ hour during dialysis with bicarbonate fluid $(\mathrm{p}<0.05)$. The rate of fall was significantly greater during dialysis with acetate than with bicarbonate fluid $(\mathrm{p}<0.02)$. The index of venous tone rose at a mean rate of $0.23(0.05) \mathrm{ml} / \mathrm{dl}$ over $40 \mathrm{~mm} \mathrm{Hg} /$ hour during dialysis with acetate fluid $(\mathrm{p}<0.01)$ and $0.20(0.05) \mathrm{ml} / \mathrm{dl}$ over $40 \mathrm{~mm} \mathrm{Hg} / \mathrm{hour}$ during dialysis with bicarbonate fluid $(p<0.01)$. Vascular resistance in the forearm increased at a mean rate of $3.6(1 \cdot 12)$ units/hour during dialysis with acetate fluid $(\mathrm{p}<0.02)$ and $4.5(1.48)$ units/hour during dialysis with bicarbonate fluid $(\mathrm{p}<0.01)$. There were no significant differences in the changes in venous tone or vascular resistance between dialysis with acetate and bicarbonate fluid.

\section{Discussion}

The results of this study point to important abnormalities of the control of the peripheral circulation during dialysis that may contribute to the development of hypotension. The normal responses to a reduction in plasma volume such as that occurring during dialysis are venoconstriction and an increase in peripheral vascular resistance. ${ }^{7}$ Both of these mechanisms help to prevent a fall in blood pressure. The venoconstriction compensates for the reduced central plasma volume and maintains cardiac filling pressures and thereby cardiac output. The increase in peripheral vascular resistance helps maintain blood pressure despite a fall in cardiac output. Our patients showed a normal increase in peripheral vascular resistance during dialysis, but paradoxically their veins dilated. This venodilatation would accentuate the fall in central blood volume and lead to a fall in cardiac filling pressures and cardiac output and then to hypotension. Evidence supporting this as the mechanism of hypotension during dialysis is that an infusion of fluid often corrects the hypotension.

The reason for the abnormal dilatation of the venous bed is unclear. It occurred equally during both types of dialysis and therefore is not due to the vasodilating properties of acetate. It does not seem to be due to autonomic dysfunction as there were appropriate changes in heart rate and peripheral resistance during dialysis, and the veins actively dilated. It is more likely that the correction of the metabolic derangements of renal failure withdrew a stimulus to venoconstriction. Whatever the mechanism, simple measures-for example, wearing support stockings-aimed at reducing pooling of blood in peripheral veins may prevent hypotension induced by dialysis.

This study was supported by a grant from the Addenbrooke's Kidney Patients' Association.

\section{References}

1 Henrich WL. Hemodynamic instability during hemodialysis. Kidney Int 1986;30:605-12. 2 Mansell MA, Wing AJ. Acetate or bicarbonate for haemodialysis. Br Med $\mathcal{J}$ 1983;287:308-9. 3 Kinet J, Soyeur D, Balland N, Saint-Remy M, Collignon P, Godon J. Hemodynamic study of hypotension during hemodialysis. Kidney Int 1982;21:868-76.

4 Bevegard BS, Shepherd JT. Changes in the tone of limb veins during supine exercise. I Appl Physiol 1965;20:1-8.

5 Greenfield ADM, Whitney RI, Mowbray FR. Methods for the investigation of peripheral blood flow. Br Med Bull 1963;19:101-4.

6 Hsu CH, Swartz RD, Somermeyer MG, Raj A. Bicarbonate hemodialysis: influence on plasma refilling and hemodynamic stability. Nephron 1984;38:202-8.

7 Abboud FM, Heistad DD, Allyn LM, Schmid PG. Reflex control of the peripheral circulation. Prog Cardiovasc Dis 1976;18:371-403.

\title{
Management of asthma in hospital: a prospective audit
}

\author{
C E BUCKNALL，C ROBERTSON，F MORAN， R D STEVENSON
}

\begin{abstract}
In a prospective study of management of asthma in hospital patients with acute asthma admitted to a single hospital over a calendar year were surveyed. Altogether 157 out of 194 admissions $(81 \%)$ were studied. The patients (16 of whom had been admitted twice and one three times) were interviewed at home about two weeks after discharge, and their hospital records were reviewed. When interviewed an appreciable proportion of patients said that their asthma had been poorly controlled after their discharge from the hospital: 54 reported regular sleep disturbance due to wheeze, 78 tightness of the chest in the morning, and 77 wheeze after climbing one flight of stairs. Patients had been described on admission as having had
\end{abstract}

Department of Respiratory Medicine, Glasgow Royal Infirmary, Glasgow G4 OSF

C E BUCKNALL, MB, MRCP, registrar

F MORAN, MB, FRCP, consultant physician

R D STEVENSON, MD, FRCP, consultant physician

Department of Mathematics, Strathclyde University, Glasgow G1 1XQ C ROBERTSON, PHD, lecturer

Correspondence to: Dr C E Bucknall, Govan Health Centre, Glasgow G51 4BJ. symptoms of deteriorating asthma for a median of three days. Closer questioning of 71 patients, however, elicited that 50 had had regular symptoms indicating poor control for weeks or months. Most patients did not know how their drugs worked, and many did not have an appropriate plan of action in the event of a further attack. In all the cases studied 114 patients were treated with oral corticosteroids, only 70 had had their previous maintenance treatment increased at the time of discharge, and 107 had a follow up appointment booked for an average of three and a half weeks after discharge.

These findings show that undersupervision and undertreatment of patients with asthma are common and not confined to those dying of the condition.

\section{Introduction}

Mortality from asthma is either static ${ }^{1}$ or rising in Britain, ${ }^{2}$ with about 2000 deaths a year. Oral and inhaled corticosteroids and $\beta_{2}$ agonists, which are effective in treating asthma, have not had any impact on this figure. Several surveys of deaths from asthma have found that some factors are preventable. ${ }^{3.5}$ For example, in the British Thoracic Association's survey of deaths from asthma in two regions of England such factors existed in 77 of 90 cases: corticosteroids and bronchodilators were underused, patients were poorly supervised, and both patients and doctors underestimated 
the severity of the fatal attack and delayed summoning help. ${ }^{5} \mathrm{~A}$ leading article on asthma in Thorax in 1978 said, "in almost no other field is the gap betweeen diagnostic and therapeutic knowledge and its general application so great."

We observed in our general clinical practice that many of these factors also applied to patients treated for acute attacks of asthma in hospital and sent home. A pilot retrospective survey of admissions for asthma to our hospital during 1983 suggested that corticosteroids were being underused in the management of asthma in hospital, many patients were discharged without any change in pre-existing treatment, and supervision of patients after the acute attack was inadequate. ${ }^{7}$ This survey also confirmed previous reports of resistance to use of the peak flow meter, an objective measure of airflow obstruction. ${ }^{58}$

The effect of differing management regimens on outcome cannot be studied retrospectively, nor will all cases of asthma necessarily be surveyed; thus we carried out a prospective audit of management of asthma.

\section{Patients and methods}

All cases of acute asthma (and episodes of wheezing illness in nonsmokers) were identified daily by staff on the general medical wards to which patients were admitted as emergencies. A patient in either of these categories was approached by one of us (CEB), who explained the nature of the survey, obtained consent to visit the patient at home about two weeks after discharge, and obtained the agreement of the patient's general practitioner. In the patient's home a semistructured interview lasting 20-30 minutes was carried out, covering a check list of some 40 items. A detailed description was obtained of the patient's history of asthma and previous treatment; events leading up to the admission to hospital; management in hospital and immediately after discharge; current symptoms of asthma; understanding of the condition; and drugs given for treatment. After about two months the case notes were reviewed and details of the severity of asthma, its management, and supervision of the patient obtained.

Information was stored on a VAX-VMS computer and data analysed with the statistical package for the social sciences (SPSSX).

\section{Results}

Of 194 admissions eligible for inclusion in the study, 157 (81\%) were followed up. The patients not followed up comprised three who died (average age 66); nine transferred within 24 hours to an adjacent chest unit; nine not seen at home as arranged (who failed to respond to a follow up telephone call or letter); four from outside Glasgow; one whose general practitioner refused permission for the study; one confused with coexisting cerebrovascular disease; one transferred to long term geriatric care; three who were readmitted to other hospitals before interview; and two vagrants admitted on six occasions largely for social reasons. Six patients who were interviewed but were found subsequently to have evidence in their case notes excluding reversibility of their airflow obstruction (usually details of a negative result of a trial of steroids) were excluded from the study.

Admissions of 139 patients over a full calendar year were investigated. Sixteen patients were admitted twice and one three times (157 admissions). The average age of the patients was 47.9 (SD 19.9) years. Altogether $70 \%$ were non-smokers.

The patients' hospital records were augmented by review of records from the asthma clinic to corroborate the diagnosis of asthma made by the team on the admitting ward. In all, 97 patients had objective evidence of reversible airflow obstruction ( 77 had a clear history and in 20 with a doubtful history a trial of steroids had yielded a positive result). A further 38 were lifelong non-smokers with a clear history of episodic wheeze typical of asthma. Eighteen had a doubtful history of wheeze and no data on lung function. Notes were not available for four patients.

In 141 admissions $(90 \%)$ the patients had received treatment for their asthma before admission to hospital, inhaled $\beta_{2}$ agonists being the commonest (133 patients). Of the 96 patients taking long term treatment, two took sodium cromoglycate alone, one sodium cromoglycate and oral steroids, six oral steroids alone, 34 oral and inhaled steroids, and 53 inhaled steroids alone. Of the 90 taking either regular inhaled steroids or sodium cromoglycate, 29 remembered to take the full daily dose less than five times a week. Only 21 patients had an arrangement to start oral corticosteroids if their asthma deteriorated, with an average starting dose of $31 \mathrm{mg}$ (range $5-60 \mathrm{mg}$ ). Fifty one had had a sudden, severe attack (developing within one hour, not helped by inhalers, and requiring medical attention) within the past three years. The median number of previous admissions to hospital with asthma was one (range $0-50$, with 12 patients recalling an undefined large number of admissions). The median number of visits to general practitioners in the preceding year for exacerbations of asthmatic symptoms was three (range 0-12, four patients recalling an undefined large number of visits). Fifty six patients attended a hospital asthma clinic, 41 attended their general practitioner regularly, and some of these patients attended both.

\section{EVENTS LEADING TO HOSPITAL ADMISSION}

On interview patients reported that their asthma had deteriorated over a median of three days (range 0-42) before admission; 56 said that their symptoms had deteriorated over less than 24 hours. In the hospital's case notes deterioration over a median of three days (range $0-42$ ) was recorded in 139 cases; for the remaining 18 deterioration for "weeks" before admission was recorded. On close questioning many patients disclosed that their asthma had been poorly controlled for a long time and that initially they had described deterioration that had been the "final straw." This was formally assessed in the final 71 patients interviewed: 21 had had episodic symptoms, but the others had had regular symptoms of poor control, seven patients for weeks and $\mathbf{4 3}$ for months before being admitted to hospital.

Seventy patients had sought help from their general practitioners at the onset of the episode leading to admission to hospital, and for 64 of these some change in treatment had been made; 42 had been given antibiotics, 28 a course of oral corticosteroids, and 11 oral bronchodilators. Immediately before admission 87 patients had been seen by either their regular or an emergency general practitioner, who treated 44, most commonly with intravenous aminophylline.

\section{ASSESSMENT AND MANAGEMENT IN HOSPITAL}

Review of case records showed that the average pulse rate on admission to hospital was 110 (SD 19) beats/minute and that 68 patients had a pulse rate over 110 beats/minute. Only 20 had peak flow rate recorded as part of the initial assessment, though subsequent recordings were made for 84 patients. Arterial gases were analysed in 117 patients, of whom 44 had an oxygen pressure of less than $8 \mathrm{kPa}$.

All patients used nebulised bronchodilators regularly during their stay in hospital. Oral corticosteroids were given to 114 patients and 32 did not receive any steroids. When steroids were to be continued after discharge (110 cases) the average daily dose of prednisolone on discharge was $18 \mathrm{mg}$. Forty seven patients were given aminophylline and 96 antibiotics. Of 94 who received oxygen, only 25 were treated with high flow (at least $35 \%$ ) oxygen.

At interview 97 patients reported that their use of an inhaler had been checked in hospital but only 32 recalled being given some explanation of their drug treatment. Fifty one patients said that their treatment had not been changed on discharge, and this was confirmed from their case records. The dose of oral or inhaled drugs, or both, had been reduced for 30 patients. Hospital review was planned for 107 cases, to take place an average of 3.5 (SD 2.0) weeks later.

The diagnosis of acute asthma was recorded on the discharge summaries for only 83 of the 157 cases $(53 \%)$, even though the medical and nursing staff reported all these patients to us as having asthma. In $135(86 \%)$ cases a diagnosis of reversible airflow obstruction or episodic wheeze in lifelong non-smokers had been recorded previously. In two cases the diagnosis was asthma and bronchitis, and in 46 it was exacerbation of chronic obstruction airways disease. Various other diagnoses were recorded for nine patients and none for 12; notes were not available for five.

\section{PATIENTS' UNDERSTANDING OF THEIR ASTHMA AND TREATMENT}

As an earlier interview may influence patients' subsequent understanding of their drug treatment we assessed only first admissions $(n=139)$ in this section. One hundred and thirteen patients thought that they would recognise a bad attack of asthma in the future, usually on the non-specific basis of increasing wheeze and tightness of the chest. Only 10 patients spontaneously mentioned sleep disturbance, six increased use of bronchodilators, and 18 decreasing efficacy of inhaled bronchodilators as specific signs of worsening asthma. Eighty seven patients said that they would either call their doctor in an emergency or, depending on the severity of the attack, go straight to hospital, but 47 had no appropriate plan of action for a further attack. On specific questioning 21 said that they had arrangements to start a course of oral steroids, but only two volunteered that this would be their response to a further attack.

The table shows the numbers of patients taking drugs when interviewed.




Patients' understanding of treatment of their asthma

\begin{tabular}{|c|c|c|c|c|}
\hline \multirow[b]{2}{*}{ Category of drug } & \multirow{2}{*}{$\begin{array}{c}\text { No }(\%) \\
\text { taking drug } \\
(n=139)\end{array}$} & \multicolumn{3}{|c|}{ No $(\%)$ of those taking drug with: } \\
\hline & & $\begin{array}{l}\text { Some idea of } \\
\text { action of drug }\end{array}$ & $\begin{array}{l}\text { No idea of } \\
\text { action of drug }\end{array}$ & $\begin{array}{l}\text { Wrong idea of } \\
\text { action of drug }\end{array}$ \\
\hline \multicolumn{5}{|l|}{$\beta_{2}$ Agonists: } \\
\hline Inhaled & $131(94)$ & $54(41)$ & $73(56)$ & $4(3)$ \\
\hline Oral or theophylline & $62(45)$ & $11(18)$ & $51(82)$ & \\
\hline \multicolumn{5}{|l|}{$\begin{array}{l}\text { Corticosteroids: } \\
\text { Corich }\end{array}$} \\
\hline Inhaled & $100(72)$ & $32(32)$ & $61(61)$ & $7(7)$ \\
\hline Oral` & $65(47)$ & $7(11)$ & $55(85)$ & $3(5)$ \\
\hline Ipratropium & $23(17)$ & $8(35)$ & $15(65)$ & \\
\hline Sodium cromoglycate & $3(2)$ & $1(33)$ & $2(66)$ & \\
\hline
\end{tabular}

^Includes some patients finishing a short course of oral steroids.

Most had no idea how their drugs worked, in particular whether they were quick acting or had a long term effect.

\section{CONTROL OF ASTHMA AFTER DISCHARGE FROM HOSPITAL}

Regular sleep disturbance after their discharge from hospital was reported by 54 patients, regular tightness of the chest requiring them to use their bronchodilator before rising from bed by 78 , and wheeze on climbing one flight of stairs by 77 . Analysis with the $\chi^{2}$ test of the 62 patients who reported no sleep disturbance or tightness of the chest in the morning and the 95 patients who did showed these two groups to be broadly similar in age and severity of previous asthma. Significantly more patients without symptoms $\left(\chi^{2}=6 \cdot 4, \mathrm{df}=1, \mathrm{p}<0.01\right)$ had been looked after in general medical wards with an interest in respiratory diseases.

\section{Discussion}

This is the first prospective survey of management of asthma in hospital to be reported and included $81 \%$ of all admissions for asthma to a single hospital over a calendar year. Assessments were performed in the patients' homes by a physician with experience of managing asthma. Most of the patients had clear histories, and most had objective evidence of reversible airflow obstruction and could be clearly differentiated from patients with an exacerbation of chronic bronchitis with minor wheeze. They had moderately severe asthma, with $61 \%$ receiving long term inhaled or oral corticosteroids. In this respect they were broadly similar to the patients in the British Thoracic Association's study, 62 (69\%) of whom had been receiving such treatment.

Several characteristics of the patients deserve mention. Only $13 \%$ had been instructed to start taking oral steroids if another severe attack occurred but only $1 \%$ mentioned steroids when specifically asked what they would do in a severe attack. Only a few patients had peak flow meters to use at home, although $32 \%$ gave a history of sudden severe attacks. Compliance of patients was judged to be fair. Less than half had been to see their general practitioner during the index attack; a common reaction of patients was that such attacks had to be tolerated and would settle with time. Indeed, $34 \%$ had no appropriate plan of action in the event of a further attack. Most patients had little understanding of the way in which their drugs could be expected to help them. These findings are similar to those of a survey of patients at an asthma clinic in Aberdeen ${ }^{10}$ and enlarge the finding of the British Thoracic Association that patients dying of asthma underestimated their disease and delayed calling help. ${ }^{5}$

Forty per cent of those who saw their practitioner were given steroids before admission to hospital and $80 \%$ received them in hospital. Instructions about dosage after discharge seemed to have been adequate, but corrective and maintenance treatment may have been inadequate as a large proportion of patients had nocturnal and early morning asthma and reduced exercise capacity at interview.

A retrospective survey of management of asthma in hospitals has shown differences between general physicians and those specialising in diseases of the chest." Significantly more of our patients who did not have symptoms of asthma at interview had been managed in medical wards with an interest in respiratory diseases. This finding, more fully documented elsewhere, ${ }^{12}$ suggests that corrective and long term treatment may be better in such wards.

Both general and hospital practitioners continue to be preoccupied with bacterial infection in asthma: $66 \%$ of patients were given antibiotics at home and $61 \%$ in hospital despite good evidence that such treatment has no effect on the duration and severity of an attack of asthma. ${ }^{13}$ Only a.small proportion of patients were treated with high flow oxygen (27\% of those receiving oxygen), and very few had peak flow measured as part of their initial assessment.

The previous regular treatment in $51 \%$ of cases was unaltered or even reduced after discharge from hospital. The median duration of increasing symptoms recorded in hospital was three days, whereas $70 \%$ of patients admitted on direct questioning to symptoms of poor control for weeks or months before admission. These findings suggest that an inappropriately short term view of the illness was being taken. The time to follow up_an average of three and a half weeks for those patients given appointments - disregards the possibility of symptoms recurring as the dose of oral steroids is decreased.

This study shows that asthma is often poorly treated in general medical units, with inadequate attention being paid to the importance of pre-existing poor control, to improvement of lung function and treatment, and to the continuing close supervision of patients in an unstable phase of their disease. Management is individual both to patients and, to some extent, to physicians. Broad generalities do, however, exist, and most physicians specialising in respiratory diseases would agree that acute asthma should be treated with high flow oxygen, nebulised bronchodilators, and oral corticosteroids and that peak flow measurements provide an important objective measurement of airflow obstruction. ${ }^{14}$

Comparisons are sometimes made between asthma and diabetes in the chronicity of disease and in treatment. Patients need to understand their condition and be able to react appropriately. This survey shows that the management of asthma, however, is often a reaction to the extreme event of status asthmaticus, and the idea of fine tuning of asthma control to achieve the respiratory equivalent of normoglycaemia is almost entirely neglected.

Long term undertreatment and undersupervision have been identified as the most important factors in preventing deaths from asthma. Our survey shows that such suboptimal management practices are common even in hospital, where a high awareness of modern treatment would be expected. We believe that extrapolation of these results might explain the apparent failure of new and effective drug treatments to reduce the mortality from asthma.

We acknowledge the support of the medical and nursing staff of the medical wards, especially those who received acute medical admissions; the patients who gave their time; and Irene Adams, who processed the manuscript.

\section{References}

1 Stewart CJ, Nunn AJ. Are asthma mortality rates changing? Br 7 Dis Chest 1985;79:229-34 2 Burney PGJ. Asthma mortality in England and Wales: evidence for a further increase 1974-84. Lancet 1986;ii:323-6.

3 MacDonald JB, MacDonald ET, Seaton A, Williams DA. Asthma deaths in Cardiff 1963-74: 53 deaths in hospital. Br Med f 1976;ii:721-3.

4 Ormerod LP, Stableforth DE. Asthma mortality in Birmingham 1975-7: 53 deaths. Br Med 7 1980;280:687-90.

5 British Thoracic Association. Death from asthma in two regions of Englañ́. Br Med $\mathcal{J}$ 1982;285:1251-5.

6 Seaton A. Asthma-contrasts in care. Thorax 1978;33:1-2.

7 Bucknall CE, Stevenson RD, Moran F. A retrospective analysis of asthma admissions to hospital. Scott Med $\mathcal{J}$ (in press)

8 Reed S, Diggle S, Cushley MJ, et al. Assessment and management of asthma in an accident and emergency department. Thorax 1985;40:897-902.

9 Bellamy D, Collins JV. "Acute" asthma in adults. Thorax 1979;34:36-9.

10 Ellis ME, Friend JAR. How well do asthma clinic patients understand their asthma? $\mathrm{Br} \mathcal{F}$ Dis Chest $1985 ; 79: 43-8$.

11 Osman J, Ormerod P, Stableforth D. Management of acute asthma: a survey of hospital practice and comparison between thoracic and general physicians in Birmingham and Manchester. $\mathrm{Br} f$ Dis Chest 1987;81:232-41.

12 Bucknall CE, Robertson C, Moran F, Stevenson RD. Differences in hospital asthma management. Lancet 1988;i:748-50.

13 Graham VAL, Milton AF, Knowles GK, Davis RJ. Routine antibiotics in hospital management of acute asthma. Lancet 1982;i:418-20.

14 Cushley MJ, Tattersfield AE. Sudden death in asthma: discussion paper. $\mathcal{J} R$ Soc Med 1983;83:662-6.

(Accepted 8February 1988) 